\title{
A Unique Investigation of Knowledge Transfer Practices within the Muslim Business Community in Edinburgh
}

\author{
Michael Fascia \\ College of Medicine, School of Clinical Science, University of Edinburgh, Scotland, UK
}

Received 16 November 2014, Accepted 19 December 2014

\begin{abstract}
:
The aim of this research was to understand the dynamisms relating to knowledge transfer processes and practices, which exist within a business community in Edinburgh Scotland. The methodology used within this study was a unique design methodology to include 20 in-depth interviews with participants from four local organizations. The sample group consisted of males aged between 20 and 70. The sample was selected to include people with different levels of management experiences. Data were analyzed using framework analysis but interpreted using a unique and multifaceted lens (POPC). Results indicated that knowledge transfer practices within this participant group are derived by continuous identification and filling of knowledge gaps from the participants' real world view. Definitions of knowledge and barriers to transfer have no justification for existence within this sphere of individual or collective perspective. Definition of a standard knowledge transfer practice within the participant group was inconclusive, if reflected from modern organizational theory. Transfer of knowledge was enacted using unfamiliar network collaborations and previously undocumented knowledge frameworks. Knowledge transfer stakeholders, gatekeepers and participants of all levels should be encouraged to understand and appreciate alternative aspects of management theory. This could align business methods currently enacted within the groups and businesses studied. Further study could then reconsider the complex relationship between social group dynamics and organizational efficiency as an individual topic.
\end{abstract}

Keywords: Knowledge, Knowledge transfer, Business, Culture, Religion, Business practices

\section{INTRODUCTION}

The importance of knowledge in a business context has been discussed since at least 1945 (Hayek, 1945) and has received consistent attention ever since. The idea that knowledge is a concept, which could and should be managed, seems not to have been seriously considered until a decade or so later, and the number of useful studies continues to increase. Current theory expounds an argument in which knowledge and knowledge transfer processes, in a business context, are embedded within a set of recognized parameters and boundaries and based on causal relationships (Davenport and Prusak, 1998). This has led to the development of various knowledge transfer theories and strategies focused on the efficiency of the transfer schema, driven by the construct of success and competitive advantage in a business context (Inkpen and Dinur, 1998).

There is an extensive debate in this regard. There are proponents who believe that knowledge creation and acquisition must be managed to attain desired efficiency levels (Goh, 2002) and those who argue that the complex, social and embedded nature of knowledge means knowledge is unable to be managed efficiently (Tsoukas, 2003). Informed by this position, 
(Gupta and Govindarajan, 2000), argue that knowledge is vital to gaining and sustaining competitive advantage as it is tacit, inimitable and immobile. Others argue that knowledge generation itself enhances a business or organizations' ability and effectiveness (Nonaka, 1994), authenticates information (Foss, 2004) and improves capability with the potential to empower future decisions and actions (Zander and Kogut, 1995).

Davenport and Prusak, (2000) further describe knowledge as multifaceted, but add that it can be conceptualized as a 'justified belief'. It is perhaps inevitable that each position has its own defined stance and merit. However, to support knowledge transfer infrastructures within a business intending to develop and prosper, more definition is needed to establish which parts of the transfer mechanism support efficiency and which parts support error correction or interventions. Thus, without greater clarity, it has been, and will continue to be an unworkable aim to establish a definitive 'correct' method of knowledge transfer, which overarches a specific business or organizational strategy.

\section{Literature Review}

Because of the complexity surrounding definition and interpretation of knowledge in a business context, the literature review consisted of the following broad scope approach.

\section{$\checkmark \quad$ Business practices \\ $\checkmark$ Theoretical dynamics \\ $\checkmark \quad$ knowledge transfer problems \\ $\checkmark$ Business Success \& Competitive Advantage}

The purpose of a broad scope was to create a centralized epistemology and any functional ontological effects of formalized knowledge understanding that encompass knowledge transfer scenarios, but are related to business practices. Thus, the study could accept that knowledge understanding in this context will mean, for the most part, the discerning and differentiating influence regarding the justified or unjustified episteme of knowledge.

This literate profile is therefore opposed to any condition of possibility within any alternative epoch. Additionally, influencing these classifications is the indeterminateness of human experiences between truth and falsehood. These precepts may then be rendered to rationalistic thinking which overshadow/ surrounding knowledge transfer interactions (table 1).

Table 1: Literature scope

\begin{tabular}{|c|c|c|c|}
\hline CONCEPT & STRATEGY & CRITERIA & LITERATURE DIRECTION \\
\hline \multirow{4}{*}{ 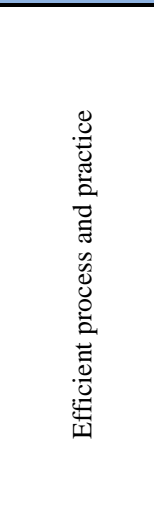 } & \multirow{4}{*}{$\begin{array}{l}\text { Systematic stages which } \\
\text { providing the knowledge } \\
\text { needed for a business or } \\
\text { organization to achieve a } \\
\text { desired goal through specific } \\
\text { criteria. } \\
\text { (Yang et al., 2010, pp. 273-289) }\end{array}$} & Generation & $\begin{array}{c}\text { Nonaka and Takeuchi (1995) } \\
\text { Boisot (2002). } \\
\text { Tannembaum et al. (2000) } \\
\text { Heisigs (2001) }\end{array}$ \\
\hline & & Communication & $\begin{array}{c}\text { Shannon (1948) } \\
\text { (Szulanski, 1996) } \\
\text { Inkpen and Dinur (1998) } \\
\text { Haworth and Savage (1989). }\end{array}$ \\
\hline & & Sharing/Learning & $\begin{array}{l}\text { Huber (1991); Choo (1998) } \\
\text { Argote et al. (1999); (Vandenbosch and } \\
\text { Higgins, 1996). }\end{array}$ \\
\hline & & Utilization/ Management & $\begin{array}{l}\text { Inkpen and Tsang (2005); Kogut and } \\
\text { Zander (1992); Hofstead (1994); Brown } \\
\text { and Duguid (1991) Teece (1981, 1982); } \\
\text { Winter (1987) }\end{array}$ \\
\hline
\end{tabular}




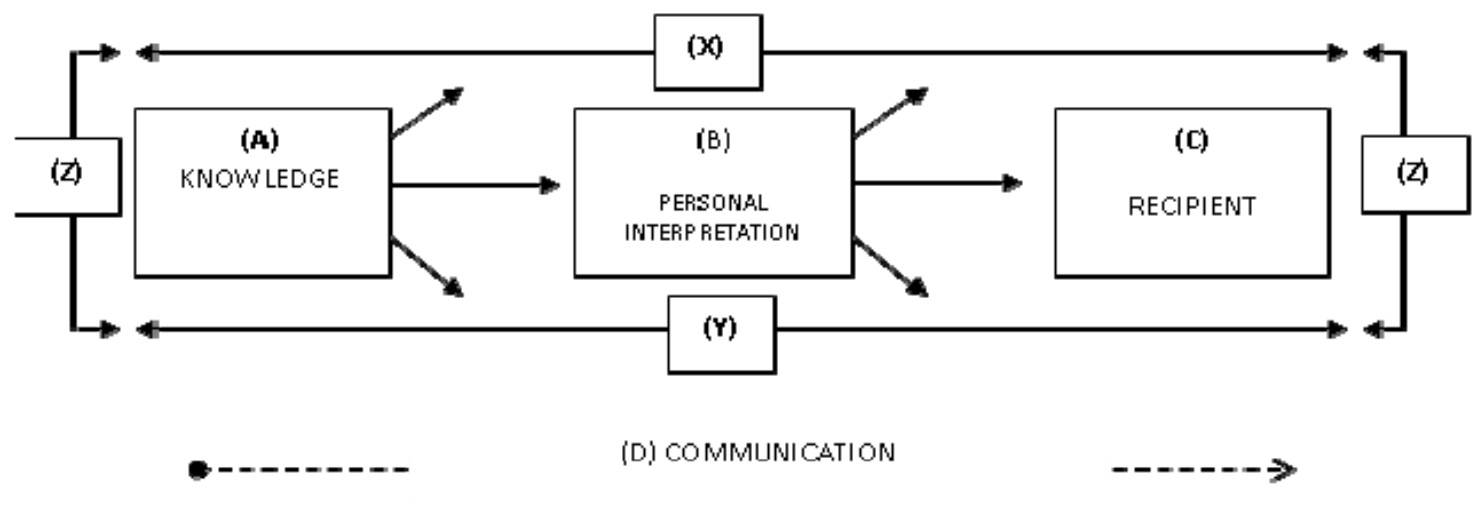

Figure 1: Simple knowledge communication or transfer pathway

Informed by this scope, figure 1 illustrates current literature positioning regarding movement of knowledge as a communication (D), where, it is presumed that knowledge (A) can move un-problematically via interpretation (B) to a recipient $(\mathrm{C})$. This flow can only take place within a process which is managed from start to finish (Z). Thus, current practices to do this are multiple, variable and inconsistent. Knowledge from this perspective only exists as an entity being observed between the boundaries of the transfer scenario $(\mathrm{X}, \mathrm{Y})$ and does not exist out-with this boundary.

Supporting this basic position, Huber (2001) considers that the practitioners (A,C) approach to any knowledge transfer will be affected by the perceived opportunity for knowledge exchange. The expectation is that it will be worthwhile to do so for both parties and therefore, both parties will be motivated to pursue efficient mechanisms to allow this. This view suggests that efficient mechanisms are essential to support any knowledge transfer process. However, Von Krogh et al. (2001) reflect what could be described as a supplementary view, in that, they agree there is a need for this overall situation to be valid, but ingress that it will be from the participants understanding of the situation, suggesting a cognitive/psychological power is necessity to underpin validity of the transfer scenario. Foucault (1984) adds that power in this context may be coextensive with resistance, are ubiquitous, as it is found in every kind of relationship and also is a condition of the possibility of any kind of relationship. Hence, these views suppose personal capabilities and thus, personal repression or oppression, directly underpin the validity of the transfer, or at least the experience of validity.

At this literal juncture, there is little doubt that this type of mechanistic assessment is predominantly directed at reducing inherent knowledge transfer errors and therefore does have clear benefits in an organizational or business context. However, although similar to Von Kroghs' view of mechanistic interpretation, a view from Kokinov (1998) slightly confuses the argument. They suggest introducing a dimensioning factor to the mechanism which will absorb a perceived problem and thus encompass the problem in a new governance framework. This means that any mechanism must still be incorporated within a structure $(X, Y)$, consist of two frameworks $(A)$ and $(B)$ which will encompass the same set of problem/answer space (C) but remain irrespective of any other epistemic value. The following diagram (figure 2) summarizes this position and is a development from the simple transfer diagram shown in the previous figure 1 . 


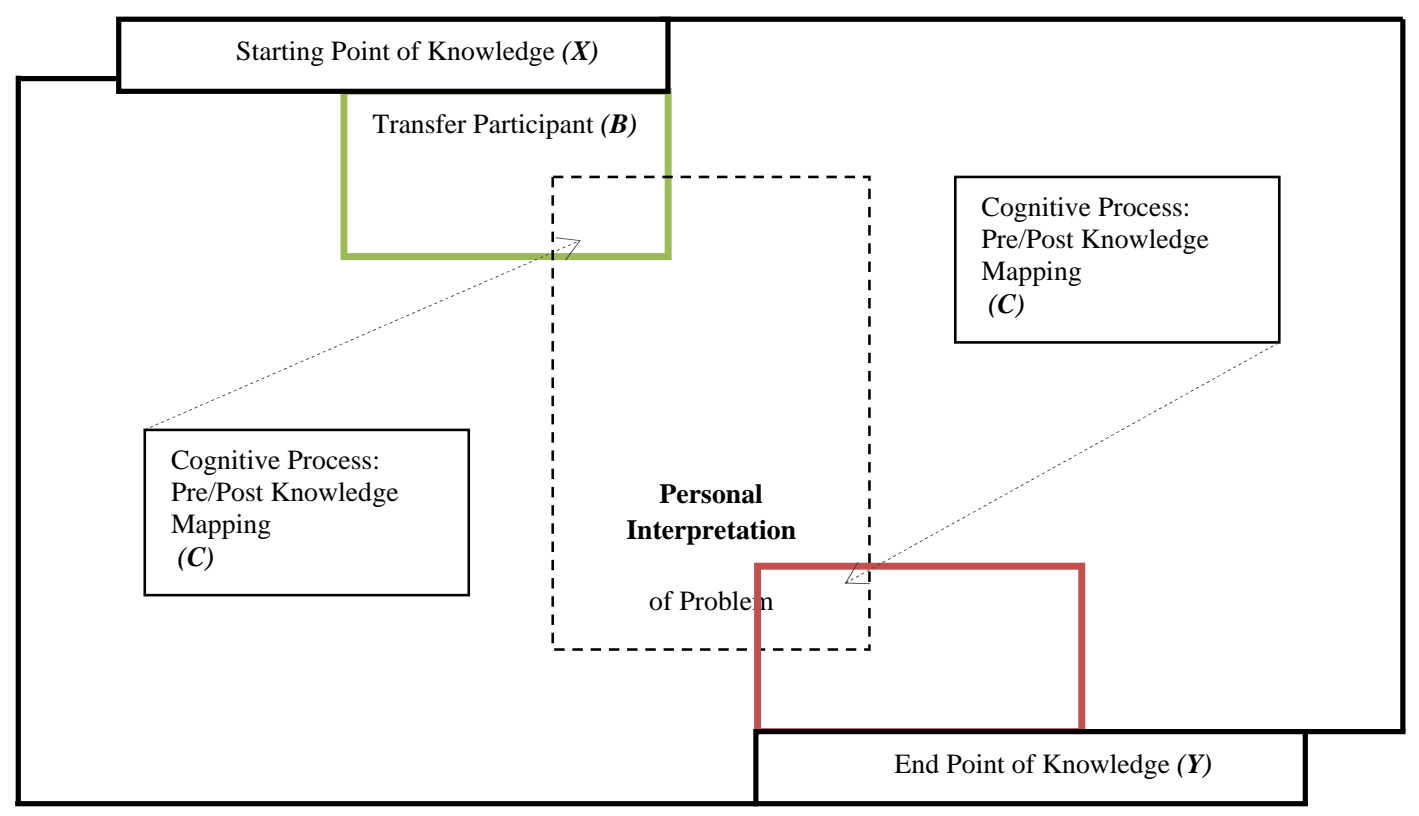

Figure 2: Complexity of transfer mechanisms and error correction

From this position, 'error correction', in terms of mechanistic knowledge transfer, and 'knowledge', in terms of interaction, are simultaneously required to support the overall transfer scenario in addition to something which builds systematic relations between individuals. Understandably, this now complicates the original/simple definitions previously outlined in figure 1. Usefully, Gentner (1983) coalesces these views by explaining that for error correction in the transfer scenario to exist, knowledge transfer practitioners must have declarative knowledge of the constraints supporting a particular problem domain. This important and fundamental argument explains that knowledge which consists of declarative representations and description, must include procedural parts relating to the transfer. That is, from Gentners' view, any knowledge being transferred is made up of constituent parts which are inherently problematic even before the transfer mechanism is started. This position would indicate that the distinction of declarative knowledge helps focus cause of error a priory and reinforce a view that the transfer mechanism is the method by which errors may be identified and resolved, since they are inherent within it. This view is supported by Petkov and Kokinov (2009), who agree that in order for knowledge transfer mechanisms to work effectively, it is the conditional attachments which must be satisfied and not the underpinning descriptions of the knowledge. Subsequently, the complexity of errors within a transfer scenario remain constant. Perhaps understandably, and because of the complex sphere of interpretation surrounding this interaction, literature often polarizes between the management of knowledge (Van Krogh and Roos, 1996) and the problems associated with transferring knowledge (Szulanski, 1996). The interactive phenomena of knowledge and knowledge transfer in relation to business and organizational development is therefore well understood, but at times, may be highly nuanced and poorly demarcated.

\section{Background}

This project aims to understand knowledge transfer processes and practices, from the perspective of knowledge transfer practitioners in the Muslim business community in Edinburgh. The rationale for this research is 
informed by 20 years of interaction this researcher has with Muslim businesses and organizations in and around Edinburgh, both as a working manager and as an advisor or consultant. Working practices ranged from IT problem solving, overlapping to $\mathrm{HR}$ and Business Development. Within this interaction, it became clear that some businesses and organizations accomplished achievements normally associated with formal business models and frameworks, such as business growth, organizational development and economic stability. Specifically, there were areas of daily business routines and social interactions involving knowledge transfer practitioners which appeared unrelated to current literature or theory, despite an obvious attachment to a business or organization aspiration trajectory. The businesses and organizational entities did not exhibit any recognizable knowledge transfer practices, but still managed to develop and maintain competitive advantage. If this is true, then this position questions fundamental concepts relative to both management theory and practice within the resource-based view (Grant, 1996) and knowledge based view of the firm (Alavi and Leidner, 2001). Given the current state of the phenomena under examination, literature and studies have not fully discussed the underlying significance relating to originating perspective points of knowledge, that is, in what form does knowledge exist before a creation point of usefulness to a business.

From a theoretical position, interpretation of knowledge prior to transfer, which may be mediated by knowledge transfer practitioner's perspectives, is not comprehensively debated within the main body of current management literature. Moreover, the degree to which any personal perspectives to knowledge is influential on the decision making capabilities of the practitioner cannot be fully identified at this littoral juncture. As such, there is no in depth examination of the knowledge transfer practitioners view, relating to subjective interpretation of knowledge from a point of existence. Further, there is little in the way of literature which explains the interactive phenomena of perspectives of knowledge involving not only practitioners cognitive positioning but personal interpretations surrounding knowledge transfer success or failure. A direct result of these observations explains why models and theories, designed to understand and control knowledge and knowledge transfer, inevitably spill over and overlap with success and competitive advantage theory.

Given the understood importance of knowledge and knowledge transfer to a business (Drucker, 1993), this qualitative study seeks to understand knowledge transfer practices within the Muslim business community in Edinburgh. It investigates how knowledge transfer practices are managed on a day to day basis, examines the route of development and justification for these practices into meaningful knowledge transfer processes, and explores the underlying perspective of knowledge from the knowledge transfer practitioners view. In particular, the study seeks explanations for such practices with resonance to both a knowledge-based (Alavi and Leidner, 2001), and a resource-based view of the firm (Grant, 1991). Finally, this position of duality polarizes the acceptance of creation and acquisition of knowledge, suggesting that without expert management, knowledge is unable to be created or have value in a business context.

This study therefore seeks answers to this position by building a parading of investigation overarched by the following broad based question.

Q1: In this participant group, what dynamisms underpin the knowledge transfer practices and processes which are used to support business success and organization development?

\section{RESEARCH METHOD}

Design: The ontology of the study is based on a constructivist paradigm (Charmaz, 2000, 2006). With an interpretivist method of qualitative data analysis. To support this position, the establishment of a literature locus based on research which indicates knowledge and knowledge transfer processes are embedded within a set of real world dimensions and are critical for a business to manage, utilised and extracted value from internal and external knowledge sources. In this respect, the design of the study adopted the four broad themes which were identified from which most literature supported theoretical arguments: Psychological, 
Organisational, Philosophical and Cultural. This further supported a robust framework for broad research questioning. To underpin this design, consideration was given to Creswell's (2009) example of a script for a qualitative research central question, which shows: "How or what" is the "meaning of" the phenomenon or phenomenology of the "culture-sharing pattern" of "central phenomenon" for "participants" at a specific "research site". In relation to this, the study adopted the following 'How' and 'What' aspects of the script and these where augmented to include 'Why' aspects. This allowed a deeper exposure to any knowledge transfer experiences from the knowledge transfer practitioner's perspective (table 2).

With respect to this positioning, analysis of congruence across knowledge transfer participants in the Muslim business community daily practices can now be situated at the core of the study. Governance of interpretive discrepancy is reduced to a cognizant understanding of facts and the critical evaluation of possibilities invoked by perceptive capabilities supported by interpretation of experiences. Thus, the understanding of cognition based around decision making which would ultimately affect knowledge transfer in the context of whichever business setting the event took place. This could be in the form of beliefs and experiential constructs underpinning decisions or it could be that the interpretation of knowledge from the participants' point of view can itself be said to represent real knowledge transfer. Either way, contextual connotation is essential, in that, the aim is to try to understand the content and complexity of meanings rather than any metric of frequency. Therefore, data collected within this archetype can allow detailed examination of specific and related practices to emerge. These practices then become relative to the knowledge transfer practitioner and not as a result of business or organisational pressures or skewed incredulities.

\section{Participant Group}

Snowball sampling (Coleman, 1958) was used to determine and build the participant group. This group consisted of 20 participants at various different managerial and staff levels across four organizations. The study employed in-depth semi-structured interviews Kvale (2006) with statistically relevant context added to location inference. Interviews were carried out across four different locations. All of the participants were of Pakistani origin but not all were born in Pakistan. All of the participants were from a Muslim background.

All participants except A1 were involved in the day to day running of either retail business or business organisations. All participants were regularly in contact both socially and in a business context. Fourteen participants were married. Participants B1/D1 owned a business outright. Participants B2-B5 owned a business in a partnership Participants A1-A5 had jobs related directly to running of the mosque, participants A4-A6 helped at the mosque but also ran or helped run a business. Participants B1/C1/C2 were related. The following table 3 shows the participant group Age; Place of birth; Married and current occupation at the time of the study.

Table 2: Design consideration

\begin{tabular}{ccc}
\hline HOW do practitioners & WHAT practices support & WHY are / is / a \\
\hline Define perspectives & Perspective definition & Perspectives important \\
Utilise methods of transfer & Knowledge transfer & Knowledge important \\
Define a framework & Business frameworks & Framework important \\
Determine governance & Governance implementation & Governance important \\
Associate knowledge with value & Business development & Development important \\
\hline Define success & Business success & Success important \\
\hline
\end{tabular}


Table 3: Participant demographics

\begin{tabular}{|c|c|c|c|c|}
\hline Participant & Age & Born in UK & Married & Occupation \\
\hline A1 & 45 & No & Yes & IMAM/ No other Business \\
\hline A2 & 72 & No & Yes & Assistant/Trustee/Business interests \\
\hline A3 & 68 & No & Yes & Assistant/Trustee/Business interests \\
\hline A4 & 42 & No & Yes & Assistant/Trustee/Business interests \\
\hline A5 & 43 & No & Yes & Assistant/Trustee/Business interests \\
\hline A6 & 28 & No & No & General Assistant \\
\hline B1 & 61 & No & Yes & Director/Business owner/Business interests \\
\hline B2 & 55 & No & Yes & Director/ Business owner/Business interests \\
\hline B3 & 64 & No & Yes & Manager/ Business owner/Business interests \\
\hline B4 & 42 & No & Yes & Manager/Business owner/Business interests \\
\hline B5 & 60 & No & Yes & Assistant/Business owner/Business interests \\
\hline B6 & 35 & No & Yes & Office Assistant \\
\hline $\mathrm{C} 1$ & 53 & No & Yes & Shop Proprietor/Business Owner/Business interests \\
\hline $\mathrm{C} 2$ & 54 & No & Yes & Shop Proprietor/Business Owner/Business interests \\
\hline C3 & 70 & No & Yes & Shop Assistant/Business interests \\
\hline $\mathrm{C} 4$ & 23 & Yes & No & Shop assistant \\
\hline C5 & 26 & Yes & No & Shop assistant \\
\hline D1 & 36 & No & No & Shop Owner \\
\hline D2 & 20 & Yes & No & Shop assistant \\
\hline D3 & 26 & Yes & No & Shop assistant \\
\hline
\end{tabular}

\section{Data Collection}

Due to the complex nature of the phenomena under investigation, data collection was developed as a two phase process. Both phase 1 and phase 2 incorporated differing locations to allow the flow of knowledge or knowledge transfer to be observed first hand, from a primary source to a secondary source via intermediary knowledge transfer points. Each location had a different number of participants, but not all participants were involved in the study at the same time. Phase one included participant observation, which proved unsuccessful due to an underestimation of complexity surrounding the participant's personal perspective and researcher bias. Phase two was therefore informed by the difficulties encountered in phase one and proved successful in capturing meaningful deep and thick data using in depth semi structured qualitative interviews (Kvale, 2006; Creswell, 2009). Dates of interviews were from April $1^{\text {st }} 2011$ to July $3^{\text {rd }}$ 2011 with a total of $(\mathrm{N}=20)$ participants. The data was collected over the four sites. There was a total of $(\mathrm{N}=37)$ interviews, 1 interview with each participant lasting approximately 1 hour, initial interview/ 1 follow up interview where possible/allowed. The following figure 3 indicates interview utilization time for the entire participant group. 


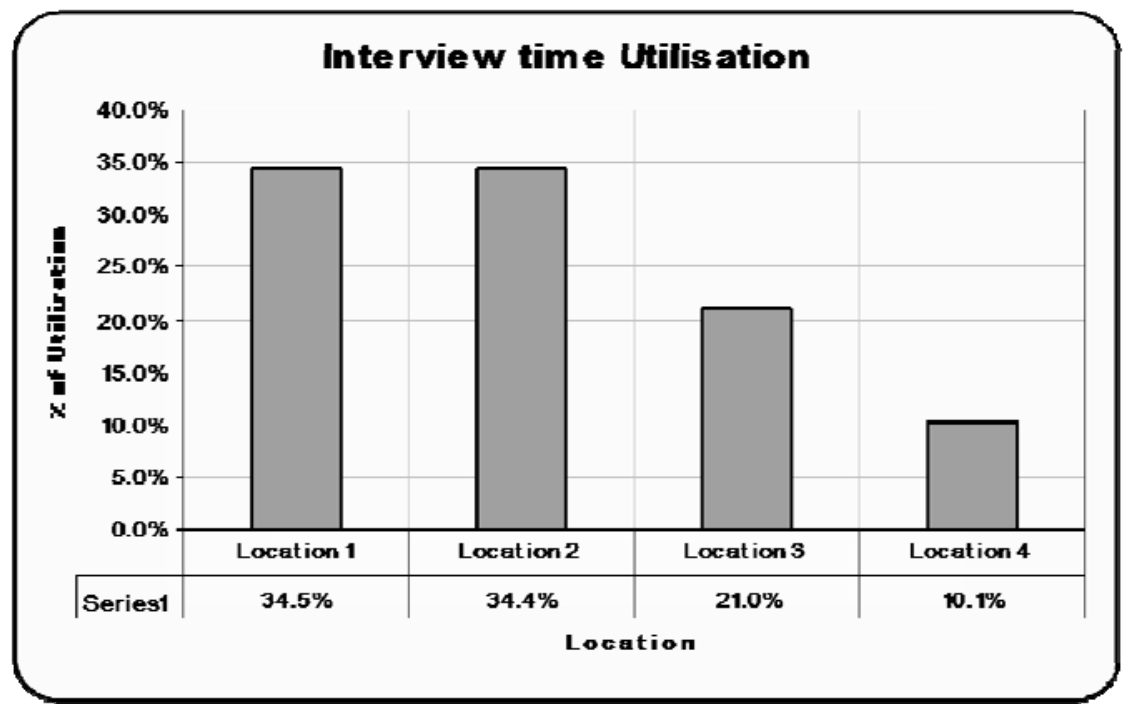

Figure 3: Interview utilization time

The following extracts indicate that from the first few interviews it was clear that the concept of knowledge and knowledge transfer is understood to have important meanings to this participant group. As the number of transcripts multiplied, second-order concepts solidified and new themes led to the categorisation and clustering of additional themes. Informed by Ochs (1979) 'transcription is theory', the interviews were transcribed as they were carried out, allowing for the creating of data items as concepts. Although complex in nature, this process was consistent with Silverman's 'constant comparative method' (Silverman 2000, p 179) in which the sample of responses is read, points of similarity and difference noted, categories generated against which to test new responses, and new categories generated.

\section{Transcript Extracts}

Extract 1

In this extract, (Participant: A3, Date: 22-0411, duration 74 mins, Location: Mosque main area) participant A3 describes his interpretation of how useful the understanding of knowledge is to him and what it means from a personal experiential point of view.

I think that any business should be guided through your own ability. I don't think it is correct that you need to check up this or that book if you don't know how to do something. You need to use your own common sense sometimes or ask someone who knows better than you. Probably I would ask the Imam.

This view by participant A3 is an important indicator for personal interpretation of knowledge, as it highlighted a similarity to Thompson and Walsham (2004) who state that knowledge is a subjective perspective of an individual's experience.

\section{Extract 2}

A further example of personal understanding of daily practices related to personal perspective is explained from participant B5, (Participant: B5, Date: 24-05-11, Duration:44mins, Location: Mosque main area), who expressed an insight of knowledge understanding from a knowledge transfer practitioners perspective by stating that; ' $a$ business can't run on its own' and in this way is also related to a main thematic category of business understanding:

I don't think it's just a case of thinking how a business should be run. I don't think it is just be run to suit yourself it's impossible. A business can't run on its own like that. You need all sorts 
of information to run it, but the way you run it depends on the people involved, not just one person to run everything, so there cannot be just someone's point of view on how a business runs. I don't think that would work, but running it right doesn't need to be complicated either.

This position of personal understanding indicated that the participant was aware of the fundamental requirement for some sort of structure and definition inside a business framework, but importantly needed to be justified by his own opinion, in that, his understanding of the situation would ensure the smooth running of the business 'you need all sorts of information to run it'. This participant therefore showed that from his personal interpretation of his real world situation, indicators of parameters and boundaries were an essential ingredient to support his daily business practices.

\section{Extract 3}

Participant D1 (Participant: D1, Date: 20/06/11, Duration: 59mins, Location: small retail outlet) gave a slightly different view of his personal understanding of knowledge. He also included knowledge awareness in a business perspective and gave further insight as to the justification of his awareness:

I am feeling very well about it (His Business) for some time now and sometimes I'd wake up in the middle of the night thinking about what I had to do the next day. When you have a business you need to think about your plan day in and day out or nothing gets done. Sometimes when I go to the mosque I can clear my head and it helps me to plan my business better. You can work things out and learn things better there. Its much easier when there is someone to ask. Everyone wants to help and explain all the things from the Quran about business. It helps me think in a better way for my business. To do it correctly and properly. That's important.

In this respect, the participant is enforcing Argotes' (1999) view that knowledge, and transfer, is the communication of known knowledge from a source to a recipient but is underpinned by justification. However, this participant's view is not the same in respect of the justification of the knowledge source, which in this case seemed to be specific and importantly not affected by cognitive dissonance.

\section{Extract 4}

Adding depth to this theme of knowledge understanding from a personal perspective, and a framework as a pre requisite of a knowledge awareness and strategy, respondent B1 (Participant: B1, Date: 04/05/11, Duration: 86 Mins, Location: Mosque Office) indicated that it is his interpretation of an ideology which is behind his understanding of knowledge:

It is quite difficult to put into simple words, example, but basically as a Muslim I know the best way for me as a person to do business.(Sic) Its not all about money all the time because of all the things you do are related to halal* (*Good, Godly, socially accepted) and haraam** (**Bad, devilish not socially acceptable).

......listen, it is 'haraam' to trade alcohol but you might make money example But it 'halal' to do good honest trade and make a little money. .....for me it's about good and bad ways. If someone asks my advice about a business venture I would always consider these things first.

This extract showed similarities to Gupta and Govindarajan (2000) who related an analogous view when discussing business models and theories which can add value to a business if properly managed. This view from this participant is in the form of an ideological perspective which could be interpreted as a model for him to follow.

\section{Extract 5}

Participant D3 (Participant:D3, Date:23/07/11,Duration: $\quad$ 45mins,Location:

Small retail outlet)

added more depth to the previous text:

....I help with this business and I hope do a good job. I do what I'm told and am honest person (sic). I know about these business things because they are in the Quran and I understand them. The Imam tells me about them and my 
friends talk about them, they are real and happen every day.

I am not sure I know much about running business but I know what's right and wrong so Allah will help me, I'm sure.

Although this participants personal knowledge was limited in terms of business and business practices as he did not own the business, his personalised world view of his own knowledge was definitive 'they (business practices) are real and happen every day'. This participant justifies his understanding of the practices, not as an amendment to existing business practices, nor as a cognitive development of his capability to understand business.

Table 4: Participant interview timing summary

\begin{tabular}{|c|c|c|c|c|c|c|c|}
\hline \multirow[b]{2}{*}{ Day } & \multicolumn{7}{|c|}{ INTERVIEW PARTICIPATION SUMMARY April 1st 2011 to July 3rd 2011} \\
\hline & Date & PARTICIPANT & $\begin{array}{l}\text { INTERVIEW LOCATIONS } \\
\text { First/Followup }\end{array}$ & INTERVIEW: & FOLLOWUP: & TOTAL & $\%$ of total Interview time \\
\hline & & & & Min & Min & Min & \\
\hline Fri & $01 / 04 / 2011$ & $\mathrm{~A} 1$ & MOSQUE/Office & 40 & 30 & 70 & \\
\hline Tue & $12 / 04 / 2011$ & A2 & MOSQUE/Hall & 44 & 22 & 66 & \\
\hline Fri & $22 / 04 / 2011$ & A3 & MOSQUE/MOSQUE & 56 & 18 & 74 & \\
\hline Thu & $28 / 04 / 2011$ & A4 & MOSQUE/Hall & 54 & 27 & 81 & \\
\hline Fri & $29 / 04 / 2011$ & A5 & MOSQUE/House & 53 & 36 & 89 & \\
\hline \multirow[t]{3}{*}{ Tue } & $03 / 05 / 2011$ & A6 & MOSQUE/Hall & 47 & 23 & 70 & \\
\hline & & & Interview Total $=12$ & & & & \\
\hline & & & Location 1 & 294 & 156 & 450 & $34.5 \%$ \\
\hline Wed & $04 / 05 / 2011$ & B1 & MOSQUE/Office & 50 & 36 & 86 & \\
\hline Wed & $11 / 05 / 2011$ & B2 & MOSQUE/Office & 44 & 23 & 67 & \\
\hline Tue & $17 / 05 / 2011$ & B3 & MOSQUE/MOSQUE & 83 & 12 & 95 & \\
\hline Wed & $18 / 05 / 2011$ & B4 & MOSQUE/Hall & 54 & 22 & 76 & \\
\hline Tue & $24 / 05 / 2011$ & B5 & MOSQUE/House & 51 & 20 & 71 & \\
\hline \multirow[t]{3}{*}{ Thu } & $26 / 05 / 2011$ & B6 & MOSQUE/MOSQUE & 39 & 14 & 53 & \\
\hline & & & Interview Total $=12$ & & & & \\
\hline & & & Location 2 & 321 & 127 & 448 & $34.4 \%$ \\
\hline Tue & 07/06/2011 & $\mathrm{Cl}$ & MOSQUE/MOSQUE & 55 & 16 & 71 & \\
\hline Thu & 09/06/2011 & $\mathrm{C} 2$ & Shop/House & 36 & 15 & 51 & \\
\hline Tue & $14 / 06 / 2011$ & $\mathrm{C} 3$ & MOSQUE/MOSQUE & 39 & 8 & 47 & \\
\hline Wed & $15 / 06 / 2011$ & $\mathrm{C} 4$ & Shop/Shop & 61 & 4 & 65 & \\
\hline \multirow[t]{3}{*}{ Thu } & $16 / 06 / 2011$ & C5 & Shop/Shop & 30 & 10 & 40 & \\
\hline & & & Interview Total $=10$ & & & & \\
\hline & & & Location 3 & 221 & 53 & 274 & $21.0 \%$ \\
\hline Mon & $20 / 06 / 2011$ & D1 & Shop & 59 & $\mathrm{~N}$ & 59 & \\
\hline Wed & $22 / 06 / 2011$ & D2 & Shop & 28 & $\mathrm{~N}$ & 28 & \\
\hline \multirow[t]{9}{*}{ Sat } & $23 / 07 / 2011$ & D3 & Shop & 45 & $\mathrm{~N}$ & 45 & \\
\hline & & & Interview Total $=3$ & & & & \\
\hline & & & Location 4 & 132 & 0 & 132 & $10.1 \%$ \\
\hline & & Total Participants & Total No. Of Interviews & Sub total Mins & Sub total Mins & $\begin{array}{l}\text { Total } \\
\text { Mins }\end{array}$ & \\
\hline & & 20 & 37 & 968 & 336 & 1304 & \\
\hline & & Interviews & 37 & & & & \\
\hline & & Participants & 20 & & & & \\
\hline & & Interview time & 1304 & & & & \\
\hline & & Interview Hours & 21.73 & & & & \\
\hline
\end{tabular}


Data Analysis

The framework approach was used to classify Data (Ritchie et al., 2013). The reason for choosing this method is that framework analysis has the ability to summarise and classify data within a thematic framework and is purposely intended to facilitate systematic analysis of qualitative data. Data analysis and collection were undertaken simultaneously. The ATLAS/ti5.0 (Muhr, 2004) qualitative analysis software was used to assist with coding, crossreferencing and storage/retrieval of data. Following a thematic logic (Frith \& Gleeson 2004), themes were carefully unpacked in an iterative process. A multi-method analytic procedure was adopted as a form of triangulation. The data were analysed to investigate its underlying inference location had on the qualitative answers and the phenomenological properties of the interview data were also investigated, using classical thematic theory and item-response theory (Hayes 1997). Differences between participants attitude to environment were therefore conclusive. In this sense, this form of thematic analysis was datadriven but interpretive in nature. (Boyatzis, 1998). The following data, (table 4), summarizes participation in each of the four data collection areas, each member of the sample group, length of the interview conducted and on which day the interview took place.

Table 5 indicates location data split into transient clusters of data items. Utilising cluster analysis in this way, provided the study with the ability to see the data in clearly defined groups, and subsequently allowed for a quick and easy visual tool for interpretation. Using an iterative process to determine domains of enquiry, data items were primarily drawn into clusters and a structured coding was developed.

This process allowed examination of final coded data using a construal code underpinned by context. Codes of data items were then created for each domain of inquiry and provided a distinct context within which to analyse and interpret answers to interview questions. This structural coding identified key data items to be associated with participants' responses. A specific code was then assigned to each datadriven item, individual text fragments were further coded for representative content. Thus, contextual foci became apparent utilising this method of cluster analysis to determine thematic codes.

Table 5 shows how Participant $A 1$ recorded $39 \%$ of his interview transcript relative to the clustered theme in relation to a context total of 44 data items. The second clustered theme accounted for $14 \%$ of the interview transcript with 16 data items. The third context indicated $23 \%$ and 26 data items. The forth context accounted for $25 \%$ of the overall interview content and 28 contextual data items. Figure 4 indicates the total clustered themes relative to all data items for all participants, (Participant A1 is highlighted for example), followed by a detailed analysis of thematic distribution.

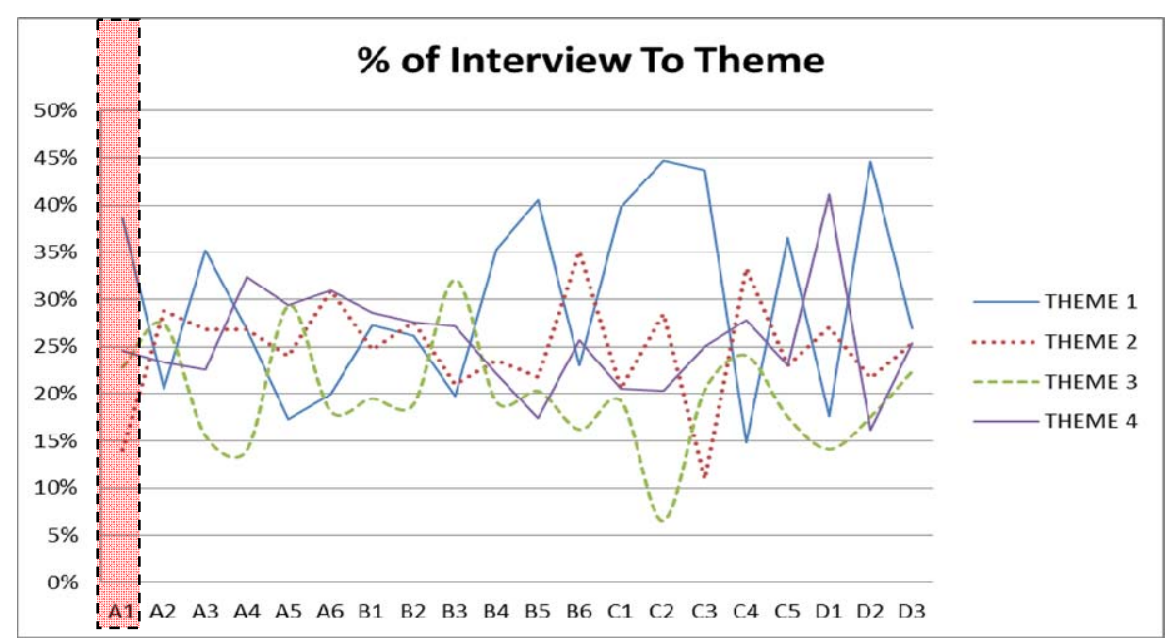

Figure 4: Total of clustered themes in relation to all data items 
Michael Fascia

Table 5: Identification of location interviews into clusters of data items

\begin{tabular}{|c|c|c|c|c|c|c|c|c|c|c|c|c|c|c|c|c|c|c|c|c|c|}
\hline \multirow{3}{*}{$\begin{array}{l}\text { CODES } \\
1.10\end{array}$} & \multirow{3}{*}{$\begin{array}{l}\text { No. } \\
\text { of } \\
\text { Data } \\
\text { Items } \\
24\end{array}$} & \multicolumn{20}{|c|}{ LOCATION } \\
\hline & & \multirow{2}{*}{$\begin{array}{l}A \\
7 \\
7\end{array}$} & \multicolumn{5}{|c|}{ MOSQUE } & \multicolumn{6}{|c|}{ MultiCulturalSociety } & \multicolumn{5}{|c|}{ Large Retail Outlet } & \multicolumn{3}{|c|}{$\begin{array}{c}\text { Small Retail } \\
\text { Outlet }\end{array}$} \\
\hline & & & & & 4 & & & 2 & & & & 5 & & 4 & & 1 & & 1 & & & \\
\hline 1.20 & 28 & 1 & 1 & & 1 & & 2 & & & 4 & & 3 & 3 & & 1 & 5 & & 3 & & 4 & 1 \\
\hline 1.30 & 48 & 8 & & 7 & & 1 & 1 & & 7 & 1 & & 7 & & & 2 & & 1 & 1 & 8 & & 4 \\
\hline 1.40 & 37 & $2 \mid$ & 1 & 2 & & 4 & 1 & 1 & 3 & & 6 & 1 & & 1 & & 4 & 1 & 2 & 1 & 6 & 1 \\
\hline 1.50 & 136 & 16 & 6 & 7 & 5 & 4 & 3 & 7 & 7 & 5 & 10 & 7 & 8 & 8 & 2 & 6 & 3 & 8 & 4 & 11 & 7 \\
\hline 1.60 & 31 & 3 & 2 & & 1 & 2 & & 2 & 1 & & 5 & & & 3 & 5 & 2 & & 2 & & 3 & \\
\hline 1.70 & 78 & 5 & 5 & 7 & 8 & 2 & 3 & 6 & & 4 & 3 & & 2 & 7 & 6 & 4 & 3 & & 2 & 6 & 5 \\
\hline 1.80 & 24 & $3 !$ & & 1 & & & 1 & 3 & & & & & 4 & 3 & & 4 & & 5 & & & \\
\hline \multirow[t]{3}{*}{1.90} & 21 & i & 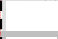 & 1 & & & & & & 2 & & 5 & & 3 & & 2 & & 5 & & 3 & \\
\hline & 427 & 44 & 15 & 25 & 19 & 13 & 11 & 21 & 18 & 16 & 24 & 28 & 17 & 29 & 55 & 28 & 8 & 27 & 15 & 33 & 18 \\
\hline & & $39 \%$ & $21 \%$ & $35 \%$ & $27 \%$ & $17 \%$ & $20 \%$ & $27 \%$ & $26 \%$ & $20 \% 3$ & $35 \% 4$ & $41 \% 2$ & $23 \%$ & $40 \%$ & $45 \%$ & $44 \%$ & $15 \%$ & $36 \%$ & $18 \%$ & $45 \%$ & $27 \%$ \\
\hline & & $\begin{array}{l}\mathbf{i} \\
\mathbf{i}\end{array}$ & & & & & & & & & & & & & & & & & & & \\
\hline 2.10 & 41 & I & 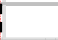 & 6 & 1 & 1 & & 4 & 1 & 2 & 1 & 6 & 1 & & 4 & 1 & 2 & 6 & 2 & 1 & 2 \\
\hline 2.20 & 24 & i & 1 & & 1 & 2 & 1 & 2 & 3 & & 4 & 1 & 2 & 1 & 1 & & 1 & 1 & & 3 & \\
\hline 2.30 & 31 & 1 & & 2 & 3 & & 4 & 1 & 2 & 1 & 1 & & 1 & 1 & 3 & & 4 & & 2 & & 5 \\
\hline 2.40 & 28 & $2 !$ & 1 & 1 & & 4 & 1 & 2 & 1 & 1 & 1 & & 4 & 1 & 2 & & 2 & 1 & 2 & 1 & 1 \\
\hline 2.50 & 24 & 1 & 4 & 1 & 1 & 1 & 1 & & 2 & & 2 & 1 & 1 & & 1 & & 3 & & 4 & & 2 \\
\hline 2.60 & 8 & $1\}$ & & 1 & & & & & & & & & & 1 & 1 & & 1 & & 1 & 1 & 1 \\
\hline 2.70 & 25 & i & 2 & & & & & & 5 & & 3 & & 4 & 1 & 2 & 1 & 1 & 1 & & 4 & 1 \\
\hline 2.80 & 28 & I & 4 & & 4 & 1 & 2 & 1 & 1 & 1 & & 4 & 1 & 2 & & 2 & 1 & 2 & 1 & 1 & \\
\hline \multirow[t]{3}{*}{2.90} & 161 & 12 & 9 & 8 & 9 & 9 & 8 & 9 & 4 & 12 & 4 & 3 & 12 & 8 & 21 & 3 & 3 & 6 & 11 & 5 & 5 \\
\hline & 370 & 16 & 21 & 19 & 19 & 18 & 17 & 19 & 19 & 17 & 16 & 15 & 26 & 15 & 35 & 7 & 18 & 17 & 23 & 16 & 17 \\
\hline & & $14 \%$ & $29 \%$ & $27 \%$ & $27 \%$ & $24 \%$ & $31 \%$ & $25 \%$ & $28 \%$ & $21 \% 2$ & $24 \% 2$ & $22 \% 3$ & $35 \%$ & $21 \%$ & $28 \%$ & $11 \%$ & $33 \%$ & $23 \%$ & $27 \%$ & $22 \%$ & $25 \%$ \\
\hline & & i & & & & & & & & & & & & & & & & & & & \\
\hline 3.10 & 6 & 1 & 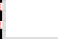 & & & & 1 & 1 & 2 & 1 & 1 & & & & & & & & & & \\
\hline 3.20 & 16 & 1 & 2 & 1 & & & & & & & 1 & 1 & & 2 & & & 4 & 1 & 2 & 1 & 1 \\
\hline 3.30 & 17 & 2 & & & 2 & 1 & 1 & 1 & & 2 & & 2 & 1 & 1 & & & & 3 & & & 1 \\
\hline 3.40 & 26 & 1 & 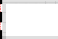 & 1 & & 1 & 1 & 2 & 1 & 1 & 1 & & 1 & 5 & & 3 & 1 & 5 & & 3 & \\
\hline 3.50 & 146 & 22 & 16 & 6 & 5 & 11 & 4 & 3 & 7 & 12 & 9 & 4 & 6 & 4 & 2 & 5 & 5 & 3 & 5 & 6 & 11 \\
\hline 3.60 & 29 & | 1 & & & 2 & 2 & & 5 & & 3 & & 1 & 1 & & 4 & 3 & & & 4 & 3 & \\
\hline 3.70 & 14 & 11 & 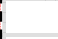 & & & 2 & 3 & & 2 & & 1 & & & 2 & 1 & 1 & 1 & & & & \\
\hline 3.80 & 19 & i & 2 & 3 & & & & & 1 & 3 & & 2 & & & 1 & 1 & 2 & 1 & 1 & & 2 \\
\hline \multirow[t]{3}{*}{3.90} & 20 & 1 & 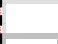 & & 1 & 5 & & 3 & & 4 & & 4 & 3 & & & & & & & & \\
\hline & 293 & 26 & 20 & 11 & 10 & 22 & 10 & 15 & 13 & 26 & 13 & 14 & 12 & 14 & 8 & 13 & 13 & 13 & 12 & 13 & 15 \\
\hline & & $23 \%$ & $27 \%$ & $15 \%$ & $14 \%$ & $29 \%$ & $18 \%$ & $19 \%$ & $19 \%$ & $32 \% 1$ & $19 \% 2$ & $20 \% 1$ & $16 \%$ & $19 \%$ & $7 \%$ & $20 \%$ & $24 \%$ & $18 \%$ & $14 \%$ & $18 \%$ & $22 \%$ \\
\hline & & $i$ & 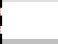 & & & & & & & & & & & & & & & & & & \\
\hline 4.10 & 12 & ' & 2 & & & & & & & & & & 3 & & 3 & 1 & & & 3 & & \\
\hline 4.20 & 52 & $|6|$ & 2 & 3 & 5 & 4 & 1 & 2 & 7 & 1 & 5 & & & 2 & 2 & 4 & & & 8 & & \\
\hline 4.30 & 16 & 1 & 2 & & 1 & 5 & & 3 & & & 1 & 1 & & & & 1 & & 2 & & & \\
\hline 4.40 & 30 & $12 !$ & 1 & 1 & 2 & 1 & 1 & 1 & & 2 & & 2 & 1 & 1 & 5 & 2 & 1 & 1 & 5 & & 1 \\
\hline 4.50 & 32 & 12 & & 3 & & 4 & 1 & 2 & 1 & 1 & 1 & & 4 & 1 & 2 & & 4 & 1 & 1 & & 4 \\
\hline 4.60 & 29 & i & 2 & & 5 & & 3 & & 4 & 1 & 2 & 1 & 1 & & 1 & 1 & & 3 & & 4 & 1 \\
\hline 4.70 & 27 & $i$ & 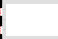 & & & 2 & & 5 & & 3 & & 4 & 1 & & 1 & 2 & 1 & & 5 & & 3 \\
\hline 4.80 & 170 & 18 & 8 & 9 & 10 & 6 & 11 & 9 & 7 & 12 & 5 & 3 & 8 & 11 & 9 & 5 & 7 & 9 & 12 & 8 & 3 \\
\hline \multirow[t]{3}{*}{4.90} & 16 & i & & & & & & & & 2 & 1 & 1 & 1 & & 2 & & 2 & 1 & 1 & & 5 \\
\hline & 384 & 28 & 17 & 16 & 23 & 22 & 17 & 22 & 19 & 22 & 15 & 12 & 19 & 15 & 25 & 16 & 15 & 17 & 35 & 12 & 17 \\
\hline & & $25 \%$ & $23 \%$ & $23 \%$ & $32 \%$ & $29 \%$ & $31 \%$ & $29 \%$ & $28 \%$ & $27 \% 2$ & $22 \% 1$ & $17 \% 2$ & $26 \%$ & $21 \%$ & $20 \%$ & $25 \%$ & $28 \%$ & $23 \%$ & $41 \%$ & $16 \%$ & $25 \%$ \\
\hline
\end{tabular}


Figure 4a, 'Thematic analysis overview', shows the composite data item cluster association to a main theme code.

Thus, data distribution indicated that a Psychological data item perspective attached to interpretive knowledge and knowledge transfer processes accounted for (29\%) of the total recorded interview data and specified the highest percentage of all the main themes. Organizational knowledge understanding also played an important role when it came to answering the interview questions and this is shown in the data items which had (25.1\%) of the total data related to it. The use of a Philosophical perspective attached to knowledge within daily business life was also important for the participants and this was shown as (19.9\%) of the total data items. Data relating to knowledge transfer experiences interpreted through a Cultural lens recorded the second highest percentage (26.1\%) and showed that the relationship of knowledge and culture in a business context is important to this participant group.

This thematic composition provided the study with an indicative relationship to previously highlighted literature review main themes; (Psychological, Organizational, Philosophical, Cultural. POPC) shown in figure 4b.

\section{Unique Approach}

Utilizing a POPC lens allowed identification and delineation of natural knowledge interaction in a transfer scenario, as a consequence, personal views and associations to knowledge and knowledge transfer scenarios emerged. This means that any emergent themes were free from localized environmental interferences, such as sporadic pressures arising from normal daily working practices. Assessment of any answer given, in relation to a POPC omphalos, allowed the study to individualize personal experiences of the participants from their own unique world view. This unique approach allowed meanings of discussion to appear on their own and not as a result of any meaning forming activity. Hence, intra-systemic and inter-systemic analysis became more meaningful/reasonable, since it exposed an interpretative personal perspective, in doing so, allowed the individual perspective of the knowledge transfer practitioner to become the researchable entity. This distinctive view would have remained hidden within standard data collection techniques associated with qualitative interviews and thematic analysis. This is because standard participant data analysis methods allow data interpretation to be overshadowed by such anomalies as: financial pressures; problematic situations; daily remedial actions or as part of periphery contextual discussions.

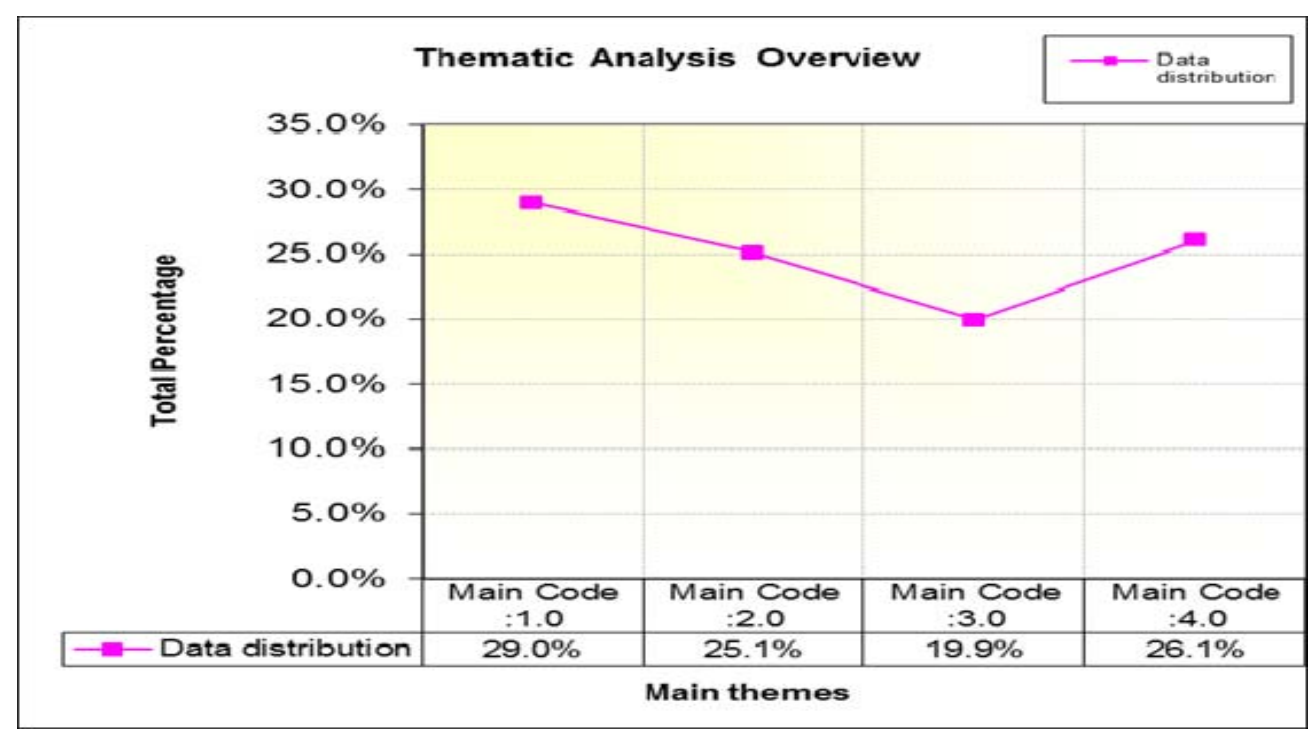

Figure 4a: Relationship to main themes 


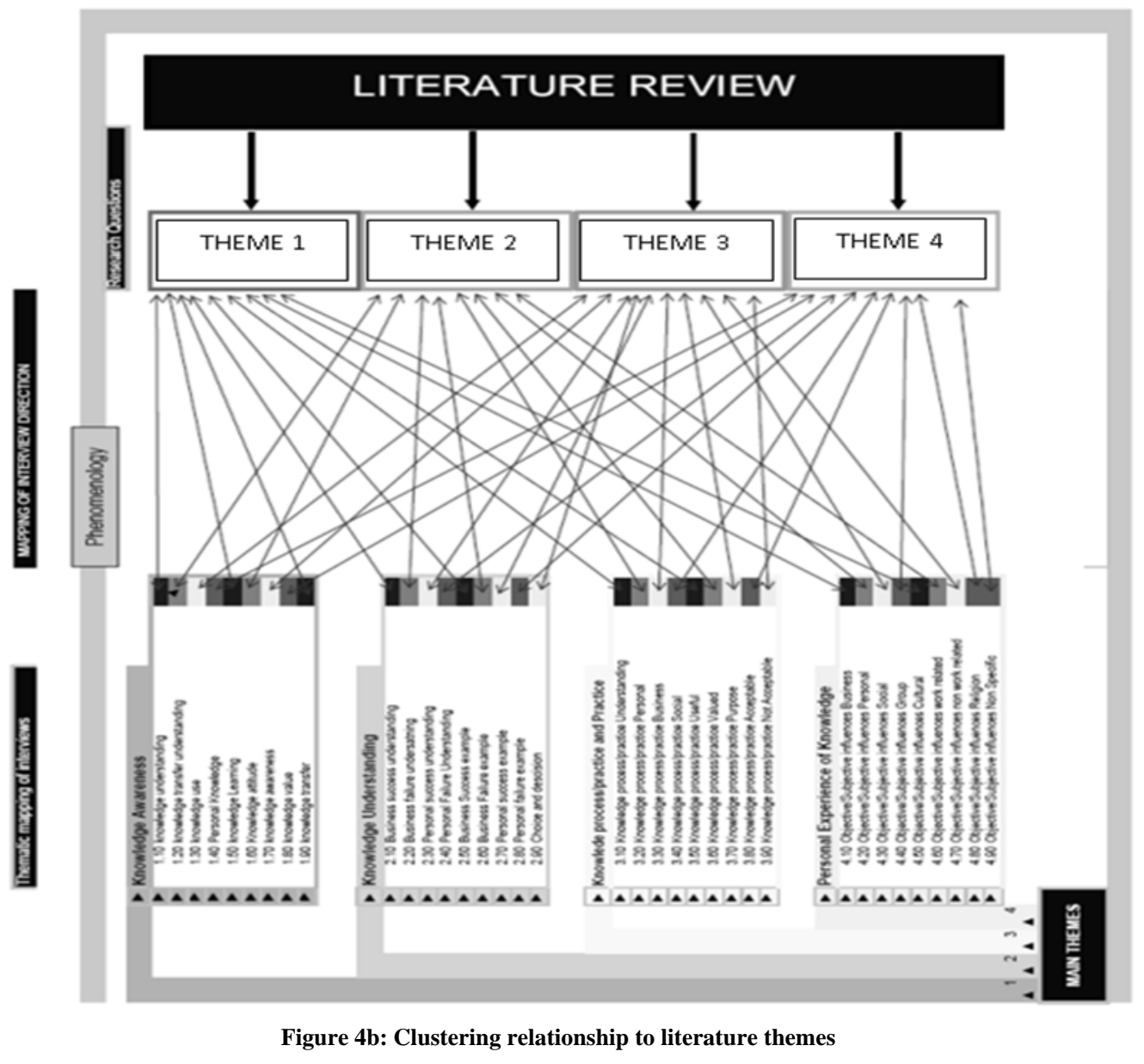

\section{RESULTS AND DISCUSSION}

The aim of this research was to add to current literature by providing a deeper theoretical understanding of knowledge transfer practices and to focus this understanding within the Muslim business community in Edinburgh. Using a unique POPC approach to the design methodology, the research fulfilled this aim by the achievement of supporting objectives.

1- A first objective established a practical, working definition for knowledge transfer within this participant group, underpinned by a philosophical episteme of knowledge, overarched by a business context.
2- A second objective, highlighted by critique and exploration of current business management models and theories, gave indication of which theme could be utilised by knowledge transfer practitioners to support knowledge transfer practices.

3- A third objective established a unique approach to methodology which allowed investigating contiguous knowledge transfer practice viewed through a phenomenological lens. This enabled collected data to become meaningful in a business context.

4- A fourth objective identified personal perspectives within this business community which could be related to current business 
practices associated with knowledge transfer theory.

\section{Key Findings}

Within this study, analysis of the data demined that key findings intersect 4 emergent themes and are aligned to current literature. However, as data analysis progressed, it became clear that when talking about knowledge, there were attitudes and posturing from the participants which literature synthesis did not reveal nor identify. Therefore, discussion of key findings will emanate from that juncture.

\section{Key Finding (1)}

Findings reveal that the association of knowledge from this participant group is derived not from a relationship to standard empirical data and models but from the conjoint levels of relational causality surrounding the unity of knowledge, to conclude a unification of perspective. This finding was identified in several ways from the participant group First, the principle ontology of the participant group, is based on the completeness surrounding the source and quality of knowledge. It is this reality which forms the fundamental premise of knowledge transfer practices according to a vehicle of unity, which in the case of this group of knowledge transfer practitioners is knowledge from the Quran. Second, the parameters and boundaries derived from the functional ontology of discourse and analytical forms apply to diverse interpretations of the knowledge transfer, they are not derived from it. Third, the unified relationship that is formalised between the participant groups is supported by both a fundamental ontology and a functional ontology. This commonality constructs a unified worldview accorded to knowledge through the episteme of unity of knowledge.

Thus, for this participant group, the analytical method of deriving functional ontology from real world knowledge transfer practices, are reformed and reconstructed by levels of unity of knowledge-induced schema, supported by common entities and relations underpinned by an alignment to a codified belief. In this participant group, social psychological processes mediate the effect of knowledge on knowledge transfer and the attention to behavioural attitudes to knowledge, supported by a cognitive capability, is due to empirical restriction of the participant rather than logical reasoning associated with empirical models and theories. In that, the a priori position of the practitioners in relation to knowledge introspection supporting knowledge transfer practices, can only be fulfilled as a personal interpretation of religion, and nothing else.

\section{Key Finding (2)}

Analysis of the data illustrated that for this group, there is only a single source for all knowledge and importantly, that it flows in only one direction, outwards from an undisputed central point of origin. Participants viewed this source of knowledge as singular definitive entity and findings show that this was not in the form of philosophical discussion nor a hypothetical proposition. Understanding the utilisation of knowledge from position may still be as a personal experience but importantly, this knowledge is already assumed to guide all things in life un-problematically, encompassing both business and personal decision making and does not distinguish a precedence of creation or definition as an experiential concept. Findings therefore reveal, that knowledge transfer utilisation from this perspective eliminates the causal effect of resistance by knowledge interpretation as there are no inferred barriers to this knowledge. As a consequence, utilisation of knowledge from this single source, can be used to develop an understanding of the personal experience which one is part of, either in a business context in the case of knowledge transfer, or for any other personal experience. In relation to knowledge transfer in a business context, knowledge from this single source is ubiquitous but can be utilised through proper guidance by scholars (Imams) which would be the case if clarity and understanding by the knowledge transfer practitioner is needed. This clear symmetry in the relationship of individual's cognitive attributes, affecting the knowledge transfer mechanism contradicts current literature, as for this participant group the underlying experiential attribute to the Quran would consciously and subconsciously affect a knowledge transfer practitioner's decision making process. Whereas current literature underpins the need for measurement of a static process which starts, stops and is measured from 
a procedural interpretation in relation to specific knowledge management practices.

\section{Key Finding (3)}

Findings show that the balancing of extrinsic and intrinsic motives is very clear and is contradictive of current literature streams. Knowledge transfer practitioners encourage intrinsic motives, especially in connection with social connection and personal knowledge and there is a constant purpose to translate and justify intrinsic motives into extrinsic motives in order to make them acquiescent to an underpinning ideology which supports all knowledge. The conduit towards such a reformation and construction of knowledge definition from the participants, is realised through social differentiations as they form distortions of knowledge which require interpretation not justification and definition. This finding is contrary to the philosophical debate in current literature which has a core focus surrounding interpretative phenomena mainly to justify knowledge from a position which supports occidental laws and policies. This is a position which fractures business and knowledge transfer communicative parameters to multiple viewpoints. For this participant group, it is the process of learning the laws of unity of knowledge by cognitive intent which gives the justification to knowledge, its meaning and also sustainability of this meaning in the transfer scenario. This cognitive capability however is in the phenomenological model of unity of knowledge which manifests the normative application of knowledge to the world-system of the knowledge transfer participants.

\section{Key Finding (4)}

Current literature reveals that in relation to specific business drivers, explicit and pragmatic reactions are situated within the realms of liberal rationalistic paradigms.

Findings reveal this cannot be wholly relevant for this participant group because the epistemological premise which grounds knowledge transfer actions as a commercial entity does not depend on alignment to a moral judgement to facilitate it. In this respect findings show that for these knowledge transfer practitioners, it is the holistic nature of daily knowledge transfer practices, encompassed within an ideological knowledge framework which support and justify knowledge transfer practices, not an empirical model driven by economic pressures. This contradicts current literature which maintains that knowledge is interpreted from many philosophical and theoretical positions, is multi-faceted, multisourced, without origin and in need of creation.

In line with current literature, findings revealed that the universality of knowledge is unconditionally accepted by this participant group as an a priori. Thus, as predicted by literature synthesis, knowledge has its ontological formalism of unification within the domain of discourse and reasoning. Nonetheless, findings from this study reveal that it is the political, economic and social structure established around a self-imposed world view which the knowledge transfer practitioner sustains cognitively in relation to a religious empowerment which has the potential to overcome knowledge related problems. Contrary to current and historical literature themes, knowledge transfer problems are not sticky' and do not contain meaning in the same context described in current literature such as barriers and interference. Findings for this group show that the concept of a 'problem' with any of the unified knowledge is out-with critical examination or discourse, therefore, there is no need to position management resources to counteract a non-existent phenomenon. This finding is in contrast to current literature which adopts individualist constraints of empiricism by assuming an adaptive hierarchical position is always necessary to resolve a perceived problem, as this receives relevance in most knowledge transfer business scenarios from economic pressures to succeed. Additionally, findings indicate that contrary to current literature, dysfunctions within the knowledge transfer scenario are seen to be the result of individual interpretation and are not attributed to the nature, quality or source of knowledge. This stance from the practitioner adopts a position of enablement not a barrier or pressure for conclusion. Thus, for this group, this position becomes the knowledge-based premise of a communitarian structure and ultimately provides a driver to interact within the knowledge transfer scenario, and allows contributory inputs not 
prescriptive adjustments to management directives or incentives.

\section{CONCLUSION}

The original aim of the study was to look at knowledge transfer practices within the participant group and compare them to current theoretical themes from literature and this research provided a deep understanding of the knowledge transfer practices in the Muslim business community in Edinburgh. Findings from this study indicate transfer of knowledge was enacted using unfamiliar network collaborations and previously undocumented integration of knowledge transfer frameworks. It is clear from this study, that for this group, comprehension of dysfunction within a knowledge transfer scenario can be seen as a relationship to knowledge of the Quran and thus produces iterative solutions of interpretation. Further, most participants adopted an almost malevolent attitude to accepted business development models described in much detail within current literature. Knowledge transfer advocacies from this participant group, irrespective of management level or organizational position, use this single source of knowledge to fill individual and collective knowledge gaps in relation to knowledge transfer scenarios used in daily work practices. In this respect, it becomes very clear that an overarching themes of religion encompasses the rhetoric of the findings. Further, core findings reveal that to knowledge transfer practitioners within this group, pre contextual definitions of knowledge and barriers to transfer have no justification for existence. Additionally, a significant factor which emerged was the representation of knowledge as a single unified entity from an undisputed source, and not, as literature emphasised, a precipitating constituent of a knowledge transfer technique, which only has value from a business perspective. Thus, through the systematic and dialectic analysis of knowledge transfer participant's daily work practices and procedures, details and dynamisms underpinning knowledge transfer processes were revealed as being previously undocumented and unique to this participant group.Findings make clear that this phenomenology is intricate and complex and cannot be acted upon easily for theoretical interpretation, for this reason, it may have been under researched in previous studies.

\section{Implications for Further Research}

Since the definition of a standard practice was inconclusive, if reflected from modern organizational theory, further research informed by this study could focus on what effects the continual struggle for organizational efficiency has on social group dynamics within a business or organization.

\section{REFERENCES}

Alavi, M. and Leidner, D. E. (2001). Review: Knowledge Management and Knowledge Management Systems: Conceptual Foundations and Research Issues. MIS Quarterly, 25 (1), pp. 107-136.

Charmaz, K. (2000). Grounded Theory: Objectivist and Constructivist Methods, In N. K. Denzin, and Y. S. Lincoln ed., Handbook of Qualitative Research, Thousand Oaks, CA: Sage, pp. 509-535.

Charmaz, K. (2006). Constructing Grounded Theory: A Practical Guide through Qualitative Analysis, Thousand Oaks, CA: Sage.

Coleman, J. (1958). Relational Analysis: The Study of Social Organizations with Survey Methods. Human Organization, 17 (4), pp. 28-36.

Davenport, T. and Prusak, L. (2000). Working Knowledge: How Organizations Manage What They Know, United States of America, Harvard Business School Press.

Drucker, P. F. (1993). Post Capitalist Society, New York: Herper Collins Publishers.

Foucault, M., Gordon, C. (1980). Power/Knowledge: Selected Interviews and Other Writings 1972-1977, London: Harvester Press, p. 197.

Foucault, M., Kritzman, L. (1984). Politics, Philosophy, Culture: Interviews and Other Writings, 1977-1984, London: Routledge, p. 38.

Foss, N. J. and Pedersen, T. (2004). Organizing Knowledge Processes in the Multinational Corporation: An Introduction. Journal of International Business Studies, 35 (5), pp. 340-349.

Goh, S. C. (2002). Managing Effective Knowledge Transfer: An Integrative Framework and Some Practice Implications. Journal of Knowledge Management, 6 (1), pp. 23-30.

Grant, R. M. (1996). Toward a Knowledge-Based Theory of the Firm. Strategic Management Journal, 17 (S2), pp. 109-122.

Hayek, F. A. (1945). The Use of Knowledge in Society. The American Economic Review, 35 (4), pp. 519-530.

Huber, G. P. (2001). Transfer of Knowledge in Knowledge Management Systems: Unexplored Issues and Suggested Studies. European Journal of Information Systems, 10 (2), pp. 72-79. 
Inkpen, A. C. and Dinur, A. (1998). Knowledge Management Processes and International Joint Ventures. Organization Science, 9 (4), pp. 454-468.

Kokinov, B. (1998). Analogy Is Like Cognition: Dynamic, Emergent, and Context Sensitive. In K. Holyoak, D. Gentner, and B. Kokinov ed., Advances in Analogy Research. Sofia, Bulgaria: NBU Press.

Muhr T. ATLAS.ti 5.0 (2004). Scientific Software Development (Computer Software). Thousand Oaks, London: Sage.

Nonaka, I. (1994). A Dynamic Theory of Organizational Knowledge Creation. Organization Science, 5 (1), pp. 14-37.

Petkov, G. and Kokinov, B. (2009). Modeling Cued Recall and Memory Illusions as a Result of Structure Mapping. In: Proceedings of the 31st Annual Conference of the Cognitive Science Society. Hillsdale, NJ: Erlbaum.

Ritchie, J., Lewis, J., Nicholls, C. M. and Ormston, R. (2013). Qualitative Research Practice, London: SAGE.

Szulanski, G. (1996). Exploring Internal Stickiness Impediments to the Transfer of Best Practice within the Firm. Strategic Management Journal, 17 (S2), pp. 27-43

Tsoukas, H. (2003). Do We Really Understand Tacit Knowledge? M. Easterby-Smith, M. Lyles, ed. The Blackwell Handbook of Organizational Learning and Knowledge Management. Blackwell, Oxford, UK, pp. 410-427.

Von Krogh, G., Nonaka, I. and Aben, M. (2001). Making the Most of Your Companies Knowledge: A Strategic Framework. Long Range Planning, 34 (4), pp. 421-439.

Zander, U. and Kogut, B. (1995). Knowledge and the Speed of the Transfer and Imitation of Organizational Capabilities: An Empirical Test. Organization Science, 6 (1), pp. 76-92. 